\title{
PENERAPAN BUDAYA KESELAMATAN TERHADAP PASIEN DAN \\ INSIDEN KESELAMATAN PASIEN YANG TERJADI DI RUMAH \\ SAKIT
}

\author{
Nuraini Sihite \\ e-mail: nurainisihite4@gmail.com
}

\section{Latar Belakang:}

Rumah sakit sebagai instansi pelayanan kesehatan yang berhubungan langsung dengan pasien harus mengutamakan pelayanan kesehatan yang aman, bermutu, antidiskriminasi dan efektif dengan mengutamakan kepentingan pasien sesuai dengan standar pelayanan rumah sakit. Keselamatan pasien merupakan hak pasien, dimana pasien berhak mendapatkan ataupun memperoleh keamanan dan keselamatan dirinya selama menjalani masa perawatan di rumah sakit.

Keselamatan pasien rumah sakit juga merupakan suatu sistem pelaporan insiden yang dirancang untuk memperoleh informasi tentang keselamatan pasien yang digunakan sebagai pembelajaran organisasi dan individu. Masalah keselamatan pasien (patient safety) pada umumnya adalah terjadi kesalahan pelayanan yang dilakukan oleh petugas meliputi kesalahan dalam kedisiplinan, komunikasi, hingga kesalahan teknis. Hampir setiap tindakan dan perawatan di rumah sakit berpotensi tinggi untuk terjadinya kesalahan medis seperti kesalahan penentuan diagnosis penyakit, keterlambatan diagnosis, pemeriksaan awal yang tidak sesuai, tidak sesuai observasi, kesalahan pada tahap pengobatan seperti salah memberikan obat, pelaksanaan terapi, dan lain-lainnya.

Keselamatan pasien difokuskan untuk pencegahan terjadinya insiden yang merugikan pasien atau untuk mencegah hal yang tidak diinginkan. Keselamatan pasien di rumah sakit adalah suatu sistem dimana rumah sakit tersebut membuat asuhan pasien lebih aman yang meliputi asesmen dari risiko, identifikasi dan penggelolaan.

Oleh karena itu, jika rumah sakit ingin menurunkan kejadian insiden keselamatan pasien maka rumah sakit harus menerapkan budaya keselamatan pasien. Dikatakan insiden keselamatan pasien adalah setiap kejadian yang tidak disengaja dan kondisi yang mengakibatkan atau berpotensi mengakibatkan cedera yang dapat dicegah pada pasien, terdiri dari kejadian tidak diharapkan (KTD), kejadian nyaris cedera (KNC), kejadian tidak cedera 
(KTC), dan kejadian potensial cedera (KPC). Sehingga untuk meningkatkan budaya keselamatan pasien, kesadaran perawat dan petugas medis tentang pentingnya keselamatan pasien juga perlu di tingkatkan.

Budaya keselamatan pasien merupakan faktor penting dalam upaya untuk mengurangi resiko yang merugikan di rumah sakit dan meningkatkan keselamatan pasien, karena budaya keselamatan pasien merupakan indikator kualitas penting dalam pelayanan kesehatan dan telah dikaitkan dengan hasil pasien yang diperoleh di rumah sakit.

\section{Metode:}

Pada proses pencarian literatur, metode yang digunakan adalah dengan mengumpulkan data-data dari beberapa jurnal dan e-book dari situs internet yang berhubungan dengan budaya keselamatan pasien dan insiden keselamatan pasien di rumah sakit.

Karena keterbatasan waktu, cakupan luas dari topik, dan untuk lebih spesifik, maka dilakukan batasan waktu pada tahun publikasinya dengan waktu minimalnya delapan tahun terakhir yaitu dari tahun 2012 dengan mengambil referensi yang terkait dengan topik yang digunakan.

\section{Hasil:}

Saat ini isu penting dan global dalam pelayanan kesehatan adalah keselamatan pasien (patient safety). keselamatan dan keamanan merupakan kebutuhan dasar manusia. Keselamatan juga merupakan hal yang sangat penting dalam setiap pelayanan keselamatan, sehingga dapat dikatakan bahwa keselamatan merupakan tanggung jawab dari pemberi jasa pelayanan kesehatan titik pelayanan kesehatan terutama pelayanan keperawatan di setiap unit perawatan baik akut maupun lanjutan harus berfokus pada keselamatan pasien baik dalam tatanan rumah sakit, komunitas maupun perawatan dirumah.

Keselamatan pasien (patient safety) adalah suatu sistem dimana rumah sakit membuat asuhan pasien lebih aman dalam upaya mencegah terjadinya cidera yang disebabkan oleh kesalahan akibat melaksanakan suatu tindakan atau tidak mengambil tindakan yang seharusnya diambil. Liza Salawati (2020)

Menciptakan budaya keselamatan pasien merupakan hal yang sangat penting. Hal tersebut dikarenakan budaya mengandung 2 komponen yaitu nilai dan keyakinan di mana 
nilai mengacu pada suatu yang diyakini oleh anggota organisasi untuk mengetahui apa yang benar dan apa yang salah sedangkan keyakinan mengacu pada sikap tentang cara bagaimana seharusnya bekerja dalam organisasi.

Ada beberapa jenis- jenis insiden yang sering terjadi di rumah sakit yaitu:

a. Kejadian tidak diharapkan (KTD)

Suatu kejadian yang mengakibatkan cedera yang tidak diharapkan pada pasien karena suatu tindakan atau karena tidak bertindak, bukan karena underlying disease atau kondisi pasien.

b. Kejadian nyaris cedera $(\mathrm{KNC})$

Suatu Insiden yang belum sampai terpapar ke pasien sehingga tidak menyebabkan cedera pada pasien.

\section{c. Kejadian tidak cedera (KTC)}

Insiden yang sudah terpapar ke pasien, tetapi tidak menimbulkan cedera, dapat terjadi karena keberuntungan.

d. Kondisi potensial cedera (KPC)

Kondisi yang sangat berpotensi untuk menimbulkan cedera, tetapi belum terjadi insiden.

\section{e. Kejadian sentinel}

Suatu KTD yang mengakibatkan kematian atau cedera yang serius.

Sistem keselamatan pasien juga merupakan prioritas utama yang harus dilaksanakan oleh rumah sakit, hal ini sangat erat kaitannya baik dengan citra rumah sakit maupun keselamatan pasien. Oleh karena itu setiap rumah sakit harus menerapkan 7 standar keselamatan pasien untuk melindungi pasien dari kejadian yang tidak diharapkan. 


\section{PEMBAHASAN:}

Saat ini isu penting dan global dalam pelayanan kesehatan adalah keselamatan pasien (patient safety). keselamatan dan keamanan merupakan kebutuhan dasar manusia.

Keselamatan juga merupakan hal yang sangat penting dalam setiap pelayanan keselamatan, sehingga dapat dikatakan bahwa keselamatan merupakan tanggung jawab dari pemberi jasa pelayanan kesehatan titik pelayanan kesehatan terutama pelayanan keperawatan di setiap unit perawatan baik akut maupun lanjutan harus berfokus pada keselamatan pasien baik dalam tatanan rumah sakit, komunitas maupun perawatan dirumah.

Keselamatan pasien (patient safety) adalah suatu sistem dimana rumah sakit membuat asuhan pasien lebih aman dalam upaya mencegah terjadinya cidera yang disebabkan oleh kesalahan akibat melaksanakan suatu tindakan atau tidak mengambil tindakan yang seharusnya diambil. Liza Salawati (2020)

Menurut Komite Keselamatan Pasien Rumah Sakit tahun 2008, keselamatan pasien adalah kondisi pasien bebas dari cedera yang tidak seharusnya terjadi yang masih bisa dihindari atau bebas dari risiko dan cidera yang berpotensial akan terjadi.

Keselamatan pasien di Rumah Sakit adalah sistem pelayanan dalam suatu Rumah Sakit yang memberikan asuhan pasien menjadi lebih aman, termasuk di dalamnya mengukur risiko, identifikasi dan pengelolaan risiko terhadap pasien, analisa insiden, kemampuan untuk belajar \& menindaklanjuti insiden serta menerapkan solusi untuk mengurangi risiko.

Keselamatan pasien merupakan suatu sistem yang sangat dibutuhkan mengingat saat ini banyak pasien yang dalam penanganannya sangat memprihatikan, dengan adanya sistem ini diharapkan dapat meminimalisir kesalahan dalam penanganan pasien baik pada pasien UGD, rawat inap maupun pada pasien poliklinik. Pelaksanaan patient safety yang masih rendah ini tidak terlepas dari pemahaman responden yang masih rendah. Rendahnya pemahaman responden ini menjadi salah satu kendala dalam pelaksanaan patient safety. Muh.Ryman Napirah, dkk (2019)

Menciptakan budaya keselamatan pasien merupakan hal yang sangat penting. Hal tersebut dikarenakan budaya mengandung 2 komponen yaitu nilai dan keyakinan di mana nilai mengacu pada suatu yang diyakini oleh anggota organisasi untuk mengetahui apa yang benar dan apa yang salah sedangkan keyakinan mengacu pada sikap tentang cara bagaimana seharusnya bekerja dalam organisasi.dengan adanya nilai dan keyakinan yang berkaitan 
dengan keselamatan pasien yang ditanamkan pada setiap anggota organisasi maka setiap anggota akan mengetahui apa yang seharusnya dilakukan dalam penerapan keselamatan pasien dengan demikian perilaku aku tersebut dapat akhirnya menjadi suatu budaya yang tertanam dalam setiap anggota organisasi berupa perilaku budaya keselamatan pasien

Budaya keselamatan pasien merupakan faktor penting dalam upaya untuk mengurangi resiko yang merugikan di rumah sakit dan meningkatkan keselamatan pasien. Budaya keselamatan pasien digunakan untuk mengukur persepsi perawat tentang budaya keselamatan pasien dan frekuensi resiko yang merugikan sering terjadi di rumah sakit.

Budaya keselamatan pasien secara garis besar dipengaruhi oleh 4 dimensi yaitu:

1. terbuka (open)

2. adil (just)

3. informatif dalam melaporkan kejadian yang terjadi (reporting) dan,

4. belajar dari kesalahan yang ada (learning).

Bersikap terbuka dan adil berarti berbagi informasi secara terbuka dan bebas, dan perlakuan adil bagi perawat ketika sebuah kejadian terjadi. Informasi yang akurat membantu dalam pencegahan kejadian dari keselamatan pasien.

Sistem pelaporan digunakan untuk memberikan informasi kepada pihak managerial mengenai kejadian yang terjadi dan sebagai pembelajaran sehingga kejadian yang sama tidak terulang. Program keselamatan pasien (Patient Safety) adalah program yang bertujuan untuk lebih memperbaiki proses pelayanan, karena sebagian besar KTD dapat merupakan kesalahan dalam proses pelayanan yang sebetulnya dapat dicegah melalui rencana pelayanan yang komprehensif dengan melibatkan pasien berdasarkan hakhaknya. Ryman Nairah (2019)

Pelaporan insiden keselamatan pasien di Rumah sakit dilakukan ketika terjadi insiden. Alur pelaporan insiden keselamatan pasien terdiri dari dua jenis yaitu: alur pelaporan insiden secara internal dan eksternal.

Laporan insiden keselamatan pasien Sub-Komite Keselamatan Pasien Rumah Sakit merupakan suatu pelaporan yang tertulis setia pada Kejadian Tidak Diharapkan (KTD), Kejadian Tidak Cedera (KTC), Kondisi Potensial Cedera(KPC) atau Kejadian Nyaris Cedera (KNC) yang menimpa pasien atau kejadian lain yang menimpa keluargadan pengunjung. Sedangkan laporan Insiden Keselamatan Pasien KKP-RS merupakan suatu pelaporan anonim 
dan tertulis ke KKP-RS setiap KTD atau KNC yang terjadi pada pasien yangkemudian dilakukan analisis penyebab, rekomendasi dan solusinya. Arfella (2018)

Yulia (2018), KKP-RS dalam Panduan Nasional keselamatan Pasien Rumah sakit membuat sitematika langkah penerapan Keselamatan Pasien Rumah Sakit (KPRS)yangterdiridari3 faseyaitu:fasepersiapan, Fase pelaksanaan dan fase evaluasi.

\section{FasePersiapan:}

Menetapkan kebijakan, rencana jangka pendek dan program tahunan keselamatan pasien rumah sakit.

\section{Fase Pelaksanaan}

Deklarasi gerakan Keselamatan pasien, program 7langkah keselamatan pasien, penerapan standar akreditasi keselamatan pasien, buat unit sebagai model (pilot project), buat program-program kusus terkait keselamatan pasien seperti, program cuci tangan, dokter penanggung jawab pasien, pelaporan dan sebagainya, bentuk forum diskusi periodik untuk pengembangan KPRS.

\section{FaseEvaluasi}

Evaluasi menyeluruh setahun sekali untuk memperbaiki program KPRS.

Perawat harus menyadari perannya sehingga harus berpartisipasi aktif dalam mewujudkan keselamatan pasien rumah sakit. Perawat harus memahami tentang apa yang dimaksud dengan keselamatan pasien rumah sakit (KPRS) serta dalam pelaksanan pelayanan harus mengetahui enam sasaran keselamatan pasien yaitu: ketepatan identifikasi pasien, peningkatan komunikasi efektif, peningkatan keamanan obat yang perlu diwaspadai, kepastian tepat lokasi, tepat prosedur, tepat pasien operasi, pengurangan resiko infeksi terkait pelayanan kesehatan, pengurangan resiko jatuh sehingga perawat dapat melaksanakan asuhan keperawatan kepada pasien secara aman. Bernadeta (2015)

Tahun 2008, Agency for Healthcare Research and Quality (AHRQ) menerbitkan sebuah buku pegangan untuk perawat dengan judul "Patient Safety and Quality: An Evidence-Based Handbook for Nurses", menurut buku ini Keselamatan pasien merupakan hal terpenting dalam perawatan kesehatan berkualitas tinggi. Banyak pekerjaan mendefinisikan keselamatan pasien dan praktek yang mencegah bahaya telah berfokus pada hasil negatif dari 
perawatan, seperti mortalitas dan morbiditas. Perawat sangat penting untuk pengawasan dan koordinasi yang mengurangi hasil merugikan tersebut.

Untuk menghindari semakin banyaknya insiden tidak diinginkan di rumah sakit Ada 7 langkah menuju keselamatan pasien

\section{Bangun kesadaran akan nilai keselamatan pasien}

Pastikan rumah sakit memiliki kebijakan yang menjabarkan apa yang harus dilakukan stafsegera setelah terjadi insiden, bagaimana langkah-langkah pengumpulan fakta harus dilakukan dan dukungan apa yang harus diberikan kepada staf, pasien dan keluarga. pastikan rumah sakit memiliki kebijakan yang menjabarkan peran dan akuntabilitas individual bilamana ada insiden. Kemudian tumbuhkan budaya pelaporan dan belajar dari insiden yang terjadi di rumah sakit.

\section{Pimpin dan dukung staf}

membangun komitmen dan fokus yang kuat dan jelas tentang keselamatan pasien di rumah sakit.

3. Integrasikan aktivitas pengelolaan risiko

kembangkan sistem dan proses pengelolaan resiko serta lakukan identifikasi dan asesmen hal yang potensial bermasalah langkah penerapan untuk rumah sakit telaah kembali struktur dan proses yang ada dalam manajemen resiko klinis dan non klinis, serta pastikan hal tersebut mencakup dan terintegrasi dengan keselamatan pasien dan staf.

\section{Kembangkan sistem pelaporan}

Pastikan stap ataupun perawatagar dengan mudah dapat melaporkan kejadian atau insiden, serta rumah sakit mengatur pelaporan kepada komite keselamatan pasien rumah sakit (KKP-RS)

\section{Libatkan dan berkomunikasi dengan pasien}

Kembangkan cara-cara komunikasi yang terbuka dengan pasien,pastikan rumah sakit memiliki kebijakan yang secara jelas menjabarkan cara-cara komunikasi terbuka tentang insiden dengan para pasien dan keluarganya nya.pastikan pasien dan keluarga mereka mendapatkan informasi yang benar dan jelas bilamana terjadi insiden.beri dukungan, 
pelatihan dan dorongan semangat kepada staf dan perawat agar selalu terbuka kepada pasien dan keluarganya.

6. Belajar dan berbagi pengalaman tentang keselamatan pasien

Dorong staf dan perawat untuk melakukan analisis agar masalah untuk belajar bagaimana dan mengapa kejadian itu timbul.

7. Cegah cedera melalui implementasi sistem keselamatan pasien

gunakan informasi yang ada tentang kejadian masalah untuk melakukan perubahan pada sistem pelayanan rumah sakit dapat menggunakan informasi yang benar dan jelas yang diperoleh dari sistem pelaporan, asesmen risiko, kajian insiden dan audit serta analisis untuk menentukan solusi yang tepat. solusi tersebut dapat mencakup penjabaran ulang sistem atau struktur dan proses penyesuaian pelatihan staf dan atau kegiatan klinis termasuk penggunaan instrumen dan menjamin keselamatan pasien. Hetty Ismainar (2019)

\section{PENUTUP}

Budaya keselamatan pasien sangat terkait dengan kejadian insiden keselamatan pasien. Dengan meningkatnya budaya keselamatan pasien maka angka kejadian insiden keselamatan pasien dapat diminimalkan. Salah satu upaya yang dapat dilakukan untuk meningkatkan penerapan budaya keselamatan pasien untuk meminimalkan insiden keselamatan pasien adalah dengan melakukan pelaporan insiden keselamatan pasien, baik KNC, KPC, KTC apalagi KTD.

Sistem keselamatan pasien juga merupakan prioritas utama yang harus dilaksanakan oleh rumah sakit, hal ini sangat erat kaitannya baik dengan citra rumah sakit maupun keselamatan pasien. Oleh karena itu setiap rumah sakit harus menerapkan 7 standar keselamatan pasien untuk melindungi pasien dari kejadian yang tidak diharapkan.

\section{DAFTAR PUSTAKA}

1. Ismainar Hetty. 2019. Keselamatan pasien di rumah sakit. Yogyakarta: Deepublish Publisher.

2. Liza Salawati. 2020. Penerapan keselamatan pasien rumah sakit. Jurnal Averrous Volume 6 No. 
3. Najihah. 2018. Budaya keselamatan pasien dan insiden keselamatan pasien di rumah sakit: literature review. Volume 3 Nomor 1.

4. Tristania Dara Arfella. 2018. Evaluasi sistem pelaporan insiden keselamatan pasien di rumah sakit. Jurnal Administrasi Kesehatan Indonesia Volume 6 No 2

5. Rangkuti D.S.R, dkk. 2018. Analisis penyebab ketidaktepatan waktu pelaporan insiden keselamatan pasien di RSU BUNDA THAMRIN. Vol 1 No2.

6. Yasmi Yulia, Hasbullah Thabrany. 2018. Faktor-Faktor yang Berhubungan dengan Budaya Keselamatan Pasien di Rumah Sakit Karya Bhakti Pratiwi Bogor Tahun 2015. Jurnal Administrasi Rumah Sakit Volume 4 Nomor 2

7. Triwibowo cecep, dkk. 2016. HANDOVER SEBAGAI UPAYA PENINGKATAN KESELAMATAN PASIEN (PATIENT SAFETY) DI RUMAH SAKIT. Jurnal Keperawatan Soedirman (The Soedirman Journal of Nursing), Volume 11, No.2.

8. Fitriana Yuni, Kurniasari pratiwi. 2018. PELAKSANAAN PATIENT SAFETY DI RUMAH SAKIT UMUM DAERAH DAN RUMAH SAKIT UMUM SWASTA BANTUL BERDASARKAN KETENTUAN UNDANG-UNDANG NOMOR 44 TAHUN 2009 TENTANG RUMAH SAKIT. Jurnal Kebidanan, 7 (1).

9. Muh. Ryman Napirah, dkk. 2019. EVALUASI KEBIJAKAN KESELAMATAN PASIEN (PATIENT SAFETY) PADA PERAWAT DI RUMAH SAKIT UMUM ANUTAPURA KOTA PALU. JURNAL KESEHATAN MASYARAKAT VOLUME 10 NOMOR 2.

10. Bernadeta, D.H. 2015. PENGETAHUAN PERAWAT TENTANG KESELAMATAN PASIEN DENGAN PELAKSANAAN PROSEDUR KESELAMATAN PASIEN RUMAH SAKIT (KPRS) DI RUMAH SAKIT PANTI WALUYA SAWAHAN MALANG. Jurnal CARE, Vol. 3, No. 1.

$\begin{array}{lllll}\text { Simamora, } & \text { R. } & \text { H. } & \text { (2018). } & \text { Buku }\end{array}$ keselamatanpasienmelaluitimbangterimapasienberbasiskomunikasiefektif: SBAR. Medan: USUpress.

Simamora, R. H. (2020). Learning of Patient Identification in Patient Safety Programs Through Clinical Preceptor Models. Medico Legal Update, 20(3), 553-556. 